\title{
Review Article \\ The Necessity of Vocational Education for Children in Preschool
}

\author{
Pham Manh $\mathrm{Ha}^{*}$ \\ VNU University of Education, 144 Xuan Thuy, Cau Giay, Hanoi, Vietnam \\ Received 01 December 2020 \\ Revised 22 February 2021; Accepted 06 September 2021
}

\begin{abstract}
Vocational education is an important activity in the process of developing the capacity to choose a career. Vocational education activities not only involve students, but are used to refer to all activities intended to support individuals of all ages and at all times in life with career understanding, make choices about career, job, job. Career guidance should be conducted right from the preschool level to prepare children for the perfect future career. The article is based on the results of analysis of Vietnam policy documents, domestic and foreign studies on vocational education as well as in-depth interviews. The article analyzes the role and tasks of vocational education for preschool children, some vocational education activities in preschools in Vietnam today, principles of vocational education for preschool children. In particular, the author also mentioned some forms of vocational education that have been implemented for preschool children today, such as field visits, vocational experience, career guidance.
\end{abstract}

Keywords: Vocational education, vocational guidance, preschool, preschool children.

\footnotetext{
* Corresponding author.

E-mail address: hapm.psy@vnu.edu.vn
}

https://doi.org/10.25073/2588-1159/vnuer.4483 


\title{
Sự cần thiết của giáo dục hướng nghiệp cho trẻ trong trường mầm non
}

\author{
Phạm Mạnh Hà* \\ Trương Đại học Giáo dục, Đại học Quốc gia Hà Nội, 144 Xuân Thủy, Cầu Giáy, Hà Nội, Việt Nam \\ Nhận ngày 01 tháng 12 năm 2020 \\ Chỉnh sửa ngày 22 tháng 02 năm 2021; Chấp nhận đăng ngày 06 tháng 9 năm 2021
}

\begin{abstract}
Tóm tắt: Giáo dục hướng nghiệp (GDHN) là hoạt động quan trọng trong quá trình phát triển năng lực lựa chọn nghề nghiệp. Hoạt động GDHN không chỉ liên quan tới học sinh, mà được dùng để chỉ tất cả các hoạt động với mục đích hỗ trợ các cá nhân ở mọi lứa tuổi và vào mọi thời điểm trong cuộc đời có hiểu biết về nghề nghiệp, đưa ra những lựa chọn về nghề nghiệp, công việc, việc làm. Việc hướng nghiệp nên được tiển hành ngay từ bậc mầm non để trẻ có sự chuẩn bị hoàn hảo cho nghề nghiệp tương lai. Bài viết dựa trên kết quả tác giả phân tích các văn bản chính sách của Việt Nam, các nghiên cứu trong và ngoài nước về GDHN cũng như kết quả phỏng vấn sâu. Bài viết phân tích về vai trò, nhiệm vụ của GDHN cho trẻ mầm non, một số hoạt động GDHN trong trường mầm non ở Việt Nam hiện nay, nguyên tắc giáo dục hướng nghiệp cho trẻ mầm non. Đặc biệt, tác giả còn đề cập đến một số hình thức GDHN đã thực hiện cho trẻ mầm non hiện nay trên thực tế như: tham quan thực tể, trải nghiệm hướng nghiệp, vui chơi hướng nghiệp.
\end{abstract}

Tù khóa: Giáo dục hướng nghiệp, hướng nghiệp, trường mầm non, trẻ mầm non.

\section{1. Đặt vấn đề}

Giáo dục hướng nghiệp (GDHN) là hoạt động quan trọng trong quá trình phát triển năng lực lựa chọn nghề nghiệp. GDHN là hệ thống các giải pháp dựa trên cơ sở tâm lý học, sinh lý học, giáo dục học,... để giúp học sinh chọn nghề phù hợp với nhu cầu xã hội, đồng thời thỏa mãn tối đa nguyện vọng, thích hợp với năng lực, sở trường và điều kiện tâm sinh lý cá nhân để họ có thể phát triển tới đỉnh cao trong nghề nghiệp, cống hiến được nhiều cho xã hội cũng như tạo lập được cuộc sống tốt đẹp cho bản thân. "Trong quá trình giáo dục hướng nghiệp, học sinh cần được tìm hiểu các lĩnh vực nghề nghiệp phổ biến trong xã hội để giúp cho việc định hướng nghề nghiệp và thấy được sự phù hợp của năng lực bản thân với yêu cầu ở nghề cụ thể,..." [1]. Quan điểm của Curry (2013) cho rằng, công việc nên có sự pha trộn

\footnotetext{
* Tác giả liên hệ.

Địa chi email: hapm.psy@ vnu.edu.vn

https://doi.org/10.25073/2588-1159/vnuer.4483
}

giữa niềm yêu thích, tinh thần vượt thử thách nhằm gặt hái thành tựu. Công việc đồng thời cần đáp ứng được sự chuyên nghiệp và phát triển cá nhân [2]. Theo Brown (2012), một người thường xuyên làm công việc nào đó sẽ tác động rất lớn đến lối sống của bản thân. Chính vì vậy, công việc có thể có ý nghĩa tâm lý rất lớn trong cuộc sống của mỗi cá nhân bởi họ đã dành rất nhiều thời gian và công sức cho cồng việc. Bên cạnh đó, tư vấn hướng nghiệp sẽ góp phần ngăn ngừa hoặc khắc phục các vấn đề liên quan đến nghề nghiệp cho các cá nhân nếu họ thật sự phù hợp với công việc hiện tại [3]. Như vậy, sự nghiệp và công việc thường được xem là một phần quan trọng trong cuộc sống của mỗi người và tư vấn hướng nghiệp có thể mang đến giá trị và hữu ích thực sự thúc đẩy sự phát triển của cá nhân và giải quyết hiệu quả các vấn đề liên quan đến công việc. Năm 1909 , Frank Parsons nhấn mạnh hướng nghiệp cho học sinh phải dựa trên năng lực, năng khiếu, hứng thú và sở thích bản thân [4]. N. K. Krupskaia (1918-1939) cũng cho thấy tính hiệu quả lao động phụ thuộc phần lớn vào 
sự phù hợp của con người đối với nghề nghiệp. Tiếp đến, nhiều nghiên cứu đã chỉ ra những nhân tố liên quan đến học sinh và trường học ảnh hưởng đến quá trình lựa chọn trường đại học (Cabrera và La Nasa, 2001) [5]. Những phân tích trên cho thấy vai trò của GDHN cho bậc học mầm non, đó là: phát hiện, hình thành và nuôi dưỡng năng lực, năng khiếu, hứng thú và sở thích của trẻ, từ đó làm bước đệm cho hoạt động nghề nghiệp của trẻ trong tương lai.

Hoạt động GDHN không chỉ liên quan tới học sinh, mà thuật ngữ này được dùng để chỉ tất cả các hoạt động với mục đích hỗ trợ các cá nhân ở mọi lứa tuổi và vào mọi thời điểm trong cuộc đời có hiểu biết về nghề nghiệp, đưa ra những lựa chọn về nghề nghiệp, công việc, việc làm. Các hoạt động GDHN có thể được tổ chức trong trường học, gia đình, các trung tâm việc làm, tổ chức, công ty, hoặc trong cộng đồng. Tuy nhiên, hiện nay ở nước ta hoạt động GDHN đang được đề cập nhiều ở bậc phổ thông. Luật Giáo dục nghề nghiệp 2014 hay một số văn bản khác như: Quyết định 522/QĐ-TTg phê duyệt Đề án "Giáo duc hướng nghiệp và định hướng phân luồng học sinh trong giáo duc phổ thông giai đoạn 2018 - 2025"; Quyết định 1665/QĐ-TTg Phê duyệt Đề án "Hỗ trợ hoc sinh, sinh viên khởi nghiệp đến năm 2025"; Quyết định 1230/QĐ-BGDĐT Ban hành Kế hoạch triển khai Đề án "Hỗ trọ" hoc sinh, sinh viên khởi nghiệp đến năm 2025" của ngành Giáo dục;... quy định chi tiết hoạt động GDHN trong các trường phổ thông (đặc biệt là trung học cơ sở và trung học phổ thông) cũng như các trường đào tạo nghề trung cấp, cao đẳng, đại học mà hầu như chưa có văn bản nào quy định hoạt động GDHN trong trường mầm non.

Bên cạnh đó, ở bậc mầm non hoạt động GDHN lại chưa được quan tâm đúng mức và đầu tư, thực hiện đúng quy trình. Nhiều quan điểm cho rằng chỉ học sinh phổ thông mới cần phải định hình học nghề gì, định hướng nghề nghiệp, tìm hiểu nhu cầu thị trường lao động. Song thực tế lại cho thấy việc hướng nghiệp nên được tiến hành từ khi còn nhỏ, ngay từ bậc mầm non để có sự chuẩn bị hoàn hảo cho nghề nghiệp tương lai. Việc GDHN sớm sẽ làm gia tăng cơ hội thành công. Trẻ cần có sự chuẩn bị và định hướng trước, vì có nhiều ngành nghề đòi hỏi cần có thời gian rèn luyện lâu dài, mà việc trẻ chỉ có năng khiếu thôi là chưa đủ. Việc định hướng nghề nghiệp muộn làm mất cơ hội phát huy hết năng lực của trẻ. Vì vậy, cần phải quan tâm GDHN cho trẻ ngay từ bậc mầm non và cần xuất phát từ chính những năng lực tiềm ẩn của trẻ. Khi phát hiện thấy trẻ có mong muốn, hay thích làm một việc gì đó, cần chú ý quan sát và xác định tiềm năng của trẻ, và giúp trẻ lên kế hoạch, tạo điều kiện cho trẻ được thỏa mãn với niềm đam mê đó.

\section{Phương pháp nghiên cứu}

Bài viết sử dụng phương pháp thu thập thông tin định tính: phân tích tài liệu và phỏng vấn sâu. Cự thể, tác giả thực hiện 18 phỏng vấn sâu, bao gồm 10 phỏng vấn sâu với giáo viên, 5 phỏng vấn sâu với cán bộ quản lý của các trường mầm non ở Hà Nội, Nghệ An và Thành phố Hồ Chí Minh và 3 phỏng vấn sâu với cha mẹ trẻ. Ngoài ra, tác giả còn phân tích các văn bản chính sách của Việt Nam, các nghiên cứu trong và ngoài nước về GDHN. Từ những kết quả đó, bài viết hướng đến phân tích về vai trò, nhiệm vụ của GDHN cho trẻ mầm non, một số hoạt động GDHN trong trường mầm non ở Việt Nam hiện nay, nguyên tắc giáo dục hướng nghiệp cho trẻ mầm non. Đặc biệt, tác giả còn trình bày hình thức GDHN đã thực hiện cho trẻ mầm non hiện nay trên thực tế như: tham quan thực tế, trải nghiệm hướng nghiệp, vui chơi hướng nghiệp.

\section{Vai trò, nhiệm vụ của giáo dục hướng nghiệp cho trẻ mầm non}

GDHN là một hoạt động trợ giúp cá nhân lựa chọn được một nghề, không chỉ phù hợp với năng lực, nguyện vọng cá nhân mà còn với phù hợp với nhu cầu của xã hội. GDHN ở bậc mầm non cũng hướng đến mục đích như bậc phổ thông, đó là nhằm mục đích giúp cho học sinh có được ý thức như là chủ thể trong sự lựa chọn nghề nghiệp, có định hướng khi chọn nghề dựa trên cơ sở hiểu biết khoa học về nghề nghiệp, 
về nhu cầu thị trường lao động cũng như năng lực, sở trường, sức khỏe của bản thân: " $O$ ' trương mầm non, nếu các hoạt động GDHN đurợc đura vào thì trẻ sẽ được tìm hiểu, biết các thông tin về nghề nghiệp sớm. Ngoài ra, trẻ còn được phát hiện, bồi dương sở thích, năng khiếu. Đó là nền tảng tốt cho việc lựa chọn nghề nghiệp twơng lai sau này của trẻ,..." (Phỏng vấn sâu số 10 , giáo viên trường mầm non $\mathrm{A}$, Thành phố Vinh, Nghệ An).

Trong truò̀ng mầm non, GDHN có các vai trò:

Một là, giúp cho trẻ có hiểu biết về thế giới nghề nghiệp, về nội dung, yêu cầu của những nghề nghiệp trong xã hội.

Hai là, giúp trẻ nhận thức được về bản thân, đánh giá được những năng lực, khả năng, nguyện vọng liên quan đến nghề nghiệp của bản thân, thấy được giá trị của bản thân cũng như những khả năng thành công trong tương lai.

Ba là, giúp trẻ rèn luyện được những năng lực, khả năng, sở thích, nguyện vọng liên quan đến nghề nghiệp.

Các nhiệm vu cu thể của của hoạt động GDHN trong truò̀ng mầm non:

i) Tổ chức cho trẻ làm quen với các ngành nghề của nền kinh tế, đặc biệt với các nghề phổ biến;

ii) Giúp trẻ tìm hiểu nhân cách, sở thích, ước $m o ̛, \ldots$ của mình để giúp các em chọn nghề phù hợp;

iii) Đổi mới nội dung GDHN trong trường mầm non qua các hình thức đa dạng khác nhau;

iv) Tăng cường phối hợp với gia đình trong GDHN cho trẻ;

v) Xây dựng mô hình thí điểm về GDHN cho trẻ;

vi) Xây dựng tài liệu đào tạo, bồi dưỡng đội ngũ giáo viên làm công tác GDHN;

vii) Tiếp tục hoàn thiện cơ sở vật chất, trang thiết bị dạy học gắn với GDHN.

GDHN trong trường mầm non được xem là một bộ phận cấu thành của giáo dục, thông qua các trò chơi, hoạt động trải nghiệm, các buổi tham quan dã ngoại sẽ giúp trẻ làm quen và tiếp xúc, tìm hiểu các loại nghề nghiệp, hình thành nhận thức, hiểu biết, sở thích về nghề nghiệp tương lai: "Trẻ khi đurợc tham gia các hoạt động tham quan, trải nghiệm rất thích thú. Nhiều trẻ khi tham gia các hoạt động này trở nên nhanh nhẹn, vui vẻ hơn hằn khi các con học trong lớp,..." (phỏng vấn sâu số 2, giáo viên trường mầm non B., Hà Nội). Do vậy, GDHN ở trường mầm non cùng với GDHN ở bậc phổ thông có tác dụng không nhỏ đối với việc thực hiện mục tiêu giáo dục, đào tạo nguồn nhân lực có chất lượng đáp ứng yêu cầu xây dựng và phát triển đất nước của Đảng, Chính phủ ta.

Thực tế, trẻ mầm non thường có những biểu hiện năng khiếu. Có được năng khiếu trong một lĩnh vực nào, trẻ sẽ dễ dàng có tiến bộ và đạt được thành công ở lĩnh vực đó. Nếu năng khiếu của trẻ không được phát hiện sớm để bồi đắp, nuôi dưỡng thì nó sẽ mất dần. Vì vậy, gia đình và giáo viên cần lưu ý xem trẻ thường làm tốt các công việc nào đó, ví dụ: trẻ thích vẽ, thích hát, chơi đàn, hay chơi một môn thể thao,... Từ đó, hãy giúp con bồi dưỡng thêm năng khiếu, có thể tạo điều kiện cho trẻ được tham gia các hoạt động tại khu văn hóa, nhà thiếu nhi, trường đào tạo năng khiếu,...

\section{Hoạt động giáo dục hướng nghiệp trong trường mầm non ở Việt Nam hiện nay}

\subsection{Một số hình thức giáo dục huoơng nghiẹp đã} thực hiện cho trẻ mầm non hiện nay

\section{a. Tham quan thực tế}

Tham quan thực tế là một hoạt động ngoại khoá trong chương trình giáo dục toàn diện học sinh và hưởng ứng cuộc vận động " $x a ̂ y$ dưng truòng hoc thân thiện, hoc sinh tích cưc" do Bộ Giáo dục và Đào tạo phát động. Đây cũng là một điều kiện tốt để các em được học tập, mở rộng kiến thức, được giao lưu, xây dựng tình đoàn kết tương trợ lẫn nhau trong cuộc sống. Đồng thời tạo điều kiện để các em có thể tự lập và biết sống có trách nhiệm. Trên thực tế, có khá nhiều trường mầm non trong cả nước đã tổ chức hoạt động tham quan thực tế gắn với chủ đề hướng nghiệp. 
Nhiều năm trở lại đây, các trường mầm non đổi mới phương pháp và mục tiêu giáo dục bằng cách chủ động tăng cường các hoạt động trải nghiệm, không chỉ bó hẹp trong khuôn viên nhà trường mà còn mở rộng ra bên ngoài. Những hoạt động này giúp trẻ năng động hơn, phát triển khả năng quan sát, ghi nhớ, sáng tạo trong mọi tình huống.

Có thể thấy được tác dụng tích cực của việc tổ chức các hoạt động tham quan thực tế cho trẻ mầm non ở ngoài trời. Mỗi hoạt động tham quan thực tế với sự chuẩn bị chu đáo về mọi mặt tạo nên những buổi học vui, khỏe, an toàn.

Nó không những trang bị kiến thức, rèn luyện kỹ năng sống, mà còn góp phần thúc đẩy công tác GDHN trong nhà trường: "Hoạt động tham quan thực tế được trường tổ chức một cách bài bản, một năm thường có 2-3 lần cho các con tham quan. Trẻ rất thich thú, phu huynh cũng ủng hộ,..." (phỏng vấn sâu số 15 , Cán bộ quản lý, trường mầm non $\mathrm{C}$., Thành phố Hồ Chí Minh).

Hộp 1: Ví dụ về hoạt động Tham quan thực tế

Dù chỉ thành lập thời gian không lâu nhưng Trường Mầm non Kangaroo (phường 9 , Thành phố Cà Mau) đã tổ chức nhiều chuyến thực tế trải nghiệm cho trẻ. Theo đó, nội dung các chuyến đi sẽ tuỳ theo kế hoạch từng tháng ứng với các chuỗi sự kiện hoạt động [6]. Hiệu trưởng Trường Mầm non Kangaroo cho biết: "Hoạt động tham quan thực tế, ngoại khoá được nhà trường chú trọng xây dưng và lên kế hoạch ngay tù những ngày đầu hoạt động. Nhà truờng sẽ lên lịch, sắp xếp địa điểm phù hợp sụ kiện trong tháng, chẳng hạn nhu tháng 12 sẽ tiến hành cho trẻ đi tham quan doanh trại quân đội. Với chủ đề nghề nghiẹp, truờng sẽ bố trí cho các bé tìm hiểu nghề nghiệp của lính cứu hoả; Tết đến thi đi chơ hoa, chơ dua hấu,...”. Trước mỗi chuyến tham quan, dã ngoại, nhà trường đều có kế hoạch chặt chẽ. Giáo viên khảo sát địa điểm, địa hình và phối hợp với đơn vị sở tại để họ hỗ trợ khi cần thiết. Ở độ tuổi này, trẻ rất hiếu động, để đảm bảo an toàn và chủ động trong mọi tình huống, thời gian tham quan trải nghiệm sẽ kéo dài từ 45-60 phút, mỗi lần di chuyển sẽ theo từng lớp. Trong suốt thời gian trải nghiệm, giáo viên theo dõi bao quát, đảm bảo các bé đều trong tầm kiểm soát. Với những lợi ích thiết thực trong việc rèn luyện trẻ theo phương pháp học trải nghiệm, bước đầu nhận được nhiều phản hồi tích cực từ phía phụ huynh.

Hiện nay, hầu hết các trường mầm non tư thục và công lập trên địa bàn Thành phố Vinh [7] đều xây dựng kế hoạch tổ chức các buổi tham quan, dã ngoại cho học sinh. Bên cạnh lựa chọn những địa điểm dã ngoại trong thành phố như công viên, siêu thị, khu vui chơi của trẻ,... thì các trường chú trọng đến việc đưa các cháu đi thăm các làng nghề, di tích lịch sử, khu du lịch sinh thái,... Vừa qua, với mục đích nâng cao kiến thức cho trẻ trong chủ đề "Ước mo của bé", giúp các bé hiểu biết thêm một số nghề nghiệp truyền thống của quê hương, đất nước, Trường Mầm non Nắng Mai đã tổ chức 1 chuyến tham quan, trải nghiệm thực tế cho các bé tại làng nghề mây tre đan ở xóm Thái Lộc, xã Nghi Thái, huyện Nghi Lộc. Đây là 1 trong những hoạt động trải nghiệm nhằm giáo dục kỹ năng sống cho trẻ, đồng thời tạo không khí vui tươi, phấn khởi, giúp trẻ gắn bó với cô giáo cũng như bạn bè và tạo sân chơi bổ ích, thiết thực. Thông qua chuyến tham quan thực tế đã hình thành cho trẻ tình yêu đối với nét văn hóa truyền thống của dân tộc. "Chúng tôi không xem đây là 1 hoạt động lễ hộ mà là hoạt động thường xuyên trong chuơng trình chính khóa của các khối lớp. Mỗi chuyến đi đều được nhà trường, giáo viên lên kế hoạch, tồ chức kỹ lương, tạo cho các bé niềm hứng thú tìm tòi, khám phá thế giới xung quanh. Việc trải nghiệm thông qua nhũng chuyến đi thực tế này vù̃a giúp trẻ mạnh dạn trong giao tiếp, vì̀a hình thành trong trẻ nhũng ước mo sau này. Và trên hết là bồi đắp cho trẻ truyền thống luu giũ và bảo tồn nhũng giá trị cao đẹp của dân tộc", 1 giáo viên chia sẻ.

b. Trải nghiệm hướng nghiệp

Hoạt động trải nghiệm là một cách học thông qua thực hành, với quan niệm việc học là quá trình tạo ra tri thức mới trên cơ sở trải nghiệm thực tế, dựa trên những đánh giá, phân tích trên những kinh nghiệm, kiến thức sẵn có 
của trẻ. Hơn nữa hoạt động trải nghiệm hướng nghiệp là cơ hội để trẻ được thực tể trực tiếp thể hiện mình trong các nghề trong xã hội. Trẻ trải nghiệm cảm giác được hóa thân thành "công dân" thông qua các công việc thú vị như: phi công, lính cứu hỏa, bác sĩ, người mẫu, kỹ sư,... để thỏa sức vui chơi và rèn luyện các kỹ năng xã hội. Đây là phương pháp học tập, hướng nghiệp kết hợp thực tiễn rất bổ ích nhằm bổ trợ cho các bài học lý thuyết ở trường học của trẻ.
Qua hoạt động trải nghiệm hướng nghiệp, trẻ được chơi trò đóng vai vào nhiều nghề nghiệp khác nhau và cùng thực hiện những công việc cơ bản của các ngành nghề đó từ lính cứu hỏa, bác sĩ nha khoa cho đến cả thợ làm bánh, chăm sóc sắc đẹp, nhà máy làm sữa, nhà máy lọc nước,,.. Thông qua đó trẻ mầm non có cơ hội được tiếp xúc thực tế với những công việc vốn dành cho người lớn và dần định hình được sở thích cho tương lai sau này của mình.

Hộp 2: ví dụ về hoạt động Trải nghiệm hướng nghiệp

Trường Mầm non 15 (Quận Tân Bình, Thành phố Hồ Chí Minh) tổ chức cho 420 học sinh trong chuyên đề "Giáo dục kỹ năng sống cho trẻ". Theo đó, chuyên đề bao gồm nhiều trạm nghề nghiệp như tiệm bánh, sân bóng đá, viện nghiên cứu, bệnh viện, thiết kế thời trang,... Ở từng trạm, mỗi học sinh được "đóng vai" thợ làm bánh, nhà khoa học, nhà thiết kế thời trang, bác sĩ, cầu thủ đá bóng, họa sĩ; qua đó các em được tìm hiểu kỹ về nghề và trải nghiệm công việc trong từng nghề. Cô Phan Thị Ánh Hiệp (Hiệu trưởng nhà trường) cho biết hoạt động trên là sân chơi lớn dành cho học sinh trong trường những ngày cuối năm học. Thông qua từng hoạt động, các em không chỉ được tìm hiểu về những nghề nghiệp trong xã hội mà còn được thỏa sức sáng tạo, tưởng tượng. "Qua các trạm nghề nghiẹp, họ sinh sẽ có cái nhì ban đầu về mỗi nghề, tù đó các em sẽ dịnh huoóng sở thich, đam mê của mình ở tùng ngành nghề. Đặc biệt, khi đã có cái nhìn về nghề nghiệp, học sinh sẽ không có sư phân biệt ngành nghề, tù̀ đó hình thành trong các em nhân cách đẹp" [8].

Ở trường Saigon Academy International School (Thành phố Hồ Chí Minh), ngoài các buổi đi dã ngoại, các tiết dạy trên lớp của giáo viên cũng thú vị không kém. Tận dụng ngay khuôn viên lớp học, sân trường trẻ sẽ được khám phá các sự vật, hiện tượng, hoạt động thú vị xung quanh như nước, cát, vẽ tranh trên kính, học Yoga, toán tư duy, chơi với dù màu,... Tuỳ lớp sẽ có các hoạt động giáo dục khác nhau, nhưng nhìn chung các phương pháp đều gắn liền với các trò chơi tạo tâm thế cho trẻ học mà chơi, chơi mà học. Ở đó trẻ là trung tâm, giáo viên chỉ đóng vai trò hướng dẫn, hỗ trợ, định hướng trẻ và đưa ra nhận xét, đánh giá khi kết thúc hoạt động. Thông qua một địa điểm cụ thể sẽ giáo dục trẻ lòng biết ơn, biết yêu thương bạn bè, sẻ chia với những người bất hạnh, tìm hiểu ngành nghề, biết thêm lễ hội cổ truyền của dân tộc,...

Như vậy, ngay ở bậc mầm non, nhà trường sẽ phải giáo dục học sinh nhận biết một số công việc, nghề nghiệp của cha mẹ, người thân như bác sĩ, giáo viên, lính cứu hỏa,... các nghề truyền thống ở địa phương và một số việc làm cơ bản trong xã hội, hướng dẫn học sinh tham gia các công việc thường ngày tại gia đình và nhà trường. Dạy học gắn liền với các hoạt động trải nghiệm là cách để các buổi lên lớp của trẻ thêm thú vị, giúp trẻ tự tích luỹ, tiếp thu kiến thức mới, tư duy theo hướng hiện đại. Tuy nhiên, hoạt động trải nghiệm ở trường mầm non hiện nay chủ yếu dưới hình thức giáo dục kỹ năng sống, chưa có kế hoạch, mục tiêu liên quan đến GDHN rõ ràng: "Ỏ trường không có văn bản chỉ đạo tù̀ trên xuống về GDHN cho trẻ mầm non, mà trường làm cũng theo hình thức giáo dục kỹ năng sống thôi, ..." (phỏng vấn sâu số 14 , cán bộ quản lý, trường mầm non L., Hà Nội).

\section{c. Vui chơi hướng nghiệp}

Hiện nay, có rất nhiều phương pháp để giáo dục trẻ, một trong số đó là phương pháp "lấy trẻ làm trung tâm". Để đạt được hiệu quả cao trong công tác chăm sóc giáo dục trẻ theo phương pháp này, bên cạnh các hoạt động hàng ngày trên lớp thì việc tổ chức các buổi vui chơi 
hướng nghiệp cũng là việc làm vô cùng quan trọng và thiết thực: "Tại trường các cô thi thoảng cũng tổ chức cho các con đi dã ngoại tại các khu vui chơi, về các con cũng có kể được làm lính cứu hoả này kia,... các con có vẻ rất thích thú. Nhưng các con ra ngoài trường như vậy, gia đình cũng lo lắng cho sự an toàn của các con,...” (phỏng vấn sâu số 17 , Cha mẹ trẻ, Hà Nội).
Ở nhiều địa phương trong cả nước, có rất nhiều khu vui chơi hướng nghiệp ra đời đáp ứng nhu cầu học hỏi và giải trí của trẻ. Vì vậy, có thể cho trẻ đến và tham gia trải nghiệm nhiều ngành nghề khác nhau ở các môi trường đó. Khi đó, qua sự hào hứng, thích thú hay khả năng hoàn thành công việc, giáo viên và gia đình sẽ dễ dàng nhận ra đâu là sở thích và năng khiếu của trẻ, để từ đó vun đắp và định hướng nghề nghiệp tương lai cho trẻ.

\begin{abstract}
Hộp 3. Ví dụ về khu vui chơi hướng nghiệp
Hiện nay tại Thành phố Hồ Chí Minh có được 2 khu vui chơi hướng nghiệp: KizCiti ở quận 4 và Vietopia ở quận 7 [9]. KizCiti là khu vui chơi hướng nghiệp đầu tiên tại Việt Nam, được đưa vào hoạt động vào cuối năm 201. KizCiti nằm trong khu công viên thiếu nhi Khánh Hội, Sài Gòn với diện tích gần $20,000 \mathrm{~m}^{2}$ có sức chứa từ $1,200-1,500$ lượt trẻ em. Đây là một thành phố thu nhỏ dành cho các bé với gần 50 ngành nghề khác nhau, khi đến với khu vui chơi này các bé sẽ được hóa thân thành những nhân vật các bé thần tượng, ngưỡng mộ như bác sĩ, kỹ sư, chú bộ đội, làm nông, cứu hỏa, tiếp viên hàng không, phi công,... Điều đặc biệt, KizCiti là một khu vui chơi kết hợp ngoài trời và trong nhà mang đến cho các bé một trải nghiệm chân thực, gần gũi nhất với cuộc sống.

Khu vui chơi giải trí giáo dục Vietopia chính thức khai trương vào năm 2014, cũng hoạt động như hình thức hướng nghiệp của KizCiti, nhưng Vietopia có quy mô lớn hơn. Vietopia nằm trong khu đô thị mới Him Lam, Quận 7 có diện tích hơn 30,000 $\mathrm{m}^{2}$ có sức chứa tới 4,500 - 5,000 lượt trẻ em. Tại đây có đến 70 ngành nghề để các bé lựa chọn với hơn 100 hoạt động đa dạng, phong phú như phi công, tiếp viên hàng không, báo chí, phóng viên, bác sĩ, cứu hỏa,... Sự khác biệt của Vietopia so với KizCiti đó chính là khuôn viên trong nhà rộng lớn thay vì ngoài trời như KizCiti, có điều hòa mát mẻ, đặc biệt trần nhà được thiết kế như bầu trời, có ngày có đêm tạo sự chân thực cho khu vui chơi.

Ở Hà Nội cũng có một số khu vui chơi hướng nghiệp dành cho trẻ mầm non như: KizCiti, Detrang Farm, Erahouse, Làng quê Việt, Tomita,...
\end{abstract}

Sau khi phân tích tình hình GDHN cho trẻ mầm non cho thấy một số ưu điểm: các trường mầm non đã có sử dụng các hình thức đa dạng khác nhau, không chỉ ở phạm vi lớp học mà còn ở ngoài lớp học để GDHN, phương pháp mang tính chủ động, tăng cường khả năng sáng tạo, năng động của trẻ, không tốn kém quá nhiều về chi phí,... Tuy nhiên, các hoạt động GDHN của các trường mầm non phần nhiều đang mang tính tự phát, chưa có sự định hướng chỉ đạo từ trên xuống, chưa thống nhất rõ phương pháp tiến hành giữa các trường, chưa tập trung hình thành hình thành năng lực, phẩm chất, kỹ năng cho trẻ, hình thức chưa thực sự đa dạng, thu hút, chưa chú trọng việc kiểm tra, đánh giá trẻ khi GDHN,... cho nên hoạt động GDHN tại các trường mầm non Việt Nam hiện nay chưa thực sự đạt mục tiêu GDHN toàn diện cho trẻ mầm non.

\subsection{Một số nguyên tắc giáo dục hướng nghiệp cho trẻ mầm non}

Qua phân tích đánh giá ưu điểm và hạn chế tình hình GDHN của trẻ mầm non trên thực tế 
cũng như phân tích văn bản chính sách và các nghiên cứu khoa học, tác giả đưa ra một số nguyên tắc GDHN cho trẻ mầm non như sau:

i) Trước hết, việc thiết kế và tổ chức thực hiện hoạt động GDHN cho trẻ mầm non cần bảo đảm phù hợp với quan điểm của Đảng, pháp luật của Nhà nước và các quy định hiện

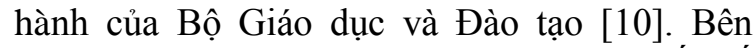
cạnh đó, các hoạt động GDHN được thiết kế đảm bảo các quy tắc ứng xử văn hoá, không phân biệt tôn giáo, vùng miền,...;

ii) Tiếp đến, về mặt khoa học, các hoạt động GDHN được xây dựng trên nền tảng lý thuyết hoạt động, lý thuyết nhân cách, lý thuyết học tập trải nghiệm và các lý luận tâm lý học, giáo dục học nói chung. Theo Tâm lý học hoạt động, tâm lý người là sản phẩm của hoạt động và giao tiếp, điều này cho thấy những năng lực, phẩm chất, kỹ năng của trẻ chỉ có thể được hình thành và phát triển thông qua các hoạt động học tập, trải nghiệm và rèn luyện;

iii) Bên cạnh đó, các chủ đề GDHN được thiết kế dựa trên tư tưởng lý thuyết kiến tạo, theo đó các chủ đề GDHN phải tạo điều kiện, cơ hội cho người học được thể hiện suy nghĩ và hành động, đóng góp chung vào kết quả của bài học, đồng thời định hướng cho người học các nội dung có lợi cho sự hình thành năng lực, phẩm chất, kỹ năng từ đó tạo ra môi trường để học sinh tích cực tham gia. Các hoạt động GDHN được thiết kế đa dạng, phong phú để người học hứng thú tham gia khám phá, lĩnh hội kiến thức;

iv) Nội dung hoạt động GDHN được thiết kế cần bám sát yêu cầu phát hiện, bồi dưỡng về phẩm chất và năng lực cho trẻ như: giới thiệu được các nghề/nhóm nghề phổ biển ở địa phương và Việt Nam; phân tích được yêu cầu về phẩm chất và năng lực của một số ngành nghề cơ bản; chỉ ra được các đặc điểm, yêu cầu cơ bản, công cụ của các ngành nghề,...;

Về hình thức tổ chức, giáo viên có thể thiết kế các hoạt động cho các chủ đề GDHN dưới các hình thức như trò chơi trong lớp học, trò chơi ở sân trường, thăm quan dã ngoại, thăm quan trải nghiệm ở các làng nghề tại địa phương, tham quan ở các khu vui chơi hướng nghiệp,... Điều này giúp cho các nội dung
GDHN thiết thực, gần gũi với đời sống thực tiễn, đáp ứng nhu cầu tham gia hoạt động vui chơi của trẻ, giúp trẻ có sự khám phá, trải nghiệm hướng nghiệp một cách chủ động, sáng tạo và hiệu quả;

v) Ngoài ra, giáo viên cũng cần chú ý đến việc kiểm tra đánh giá kết quả trẻ thực hiện chủ đề GDHN. Mục đích đánh giá nhằm thu thập thông tin chính xác, kịp thời, có giá trị về mức độ đáp ứng yêu cầu cần đạt, sự tiến bộ của trẻ trong và sau quá trình trẻ vui chơi, học tập, trải nghiệm. Kết quả đánh giá là căn cứ để giáo viên định hướng cho trẻ tiếp tục rèn luyện bản thân. Nội dung đánh giá là các biểu hiện về phẩm chất và năng lực mà trẻ đã hình thành trong quá trình tham gia học tập chương trình GDHN. Các yêu cầu cần đạt về phẩm chất và năng lực của trẻ được đánh giá thông qua hoạt động theo chủ đề, quá trình tham gia hoạt động tập thể và những sản phẩm của trẻ trong mỗi hoạt động.

\section{Kết luận}

Hoạt động GDHN hướng tới một cá nhân cụ thể với đầy đủ với các đặc điểm nhân cách, thể chất, hoàn cảnh, điều kiện gia đình cụ thể, qua đó định hướng cho cá nhân lựa chọn một nghề có trong một bối cảnh xã hội, giúp cá nhân vừa phát triển được nhân cách, đảm bảo được cuộc sống gia đình đồng thời vừa đóng góp được cho sự phát triển chung của xã hội. Đích cuối cùng của hoạt động GDHN là giúp cá nhân phát triển được tối đa khả năng, năng lực của bản thân, đảm bảo cho sự phát triển nghề nghiệp của cá nhân đó.

Việc GDHN cho trẻ mầm non là một vấn đề vô cùng quan trọng, tuy nhiên không phải giáo viên và gia đình nào cũng nhận thức được điều nay. Những sở thích của trẻ là dấu hiệu quan trọng mà gia đình, nhà trường cần lưu ý, ghi nhớ khi GDHN cho trẻ. Một điều cần lưu ý là việc GDHN cho trẻ mầm non cần dựa trên năng lực và nguyện vọng của trẻ.

Hiện nay, ở các trường mầm non trong cả nước đã có một số các hình thức GDHN cho trẻ như: tham quan thực tế, trải nghiệm hướng nghiệp hay vui chơi hướng nghiệp. Thông qua 
đó trẻ mầm non có cơ hội được tiếp xúc thực tế với những công việc vốn dành cho người lớn và dần định hình được sở thích cho tương lai sau này của mình. Tuy nhiên, trong nhiều trường hợp việc GDHN cho trẻ lại được thực hiện theo cách áp đặt. Điều đó vô hình chung làm giảm khả năng của trẻ, đồng thời trẻ sẽ không thể phát huy đúng năng lực của bản thân mình trong cuộc sống. Ngoài ra, hoạt động GDHN ở các trường mầm non đang được thực hiện dưới hình thức giáo dục kỹ năng sống hoặc mang tính tự phát, cho trẻ tìm hiểu, làm quen với nghề nghiệp. Ngoài ra, hoạt động GDHN chưa có văn bản chỉ đạo, hướng dẫn cũng như chưa có kế hoạch cụ thể, rõ ràng. Hơn nữa, hoạt động GDHN chưa có sự phối hợp chặt chẽ giữa lãnh đạo nhà trường, giáo viên và phụ huynh.

Như vậy, trong thời gian tới, để hoạt động GDHN đạt hiệu quả cần phải quan tâm tới một số vấn đề như: sửa đổi chương trình giáo dục mầm non theo hướng làm rõ mục tiêu, phương pháp, hình thức GDHN cho trẻ, ban hành các văn bản hướng dẫn chỉ đạo từ các cơ quan ban ngành; hoạt động tuyên truyền nâng cao nhận thức cho ban giám hiệu nhà trường, giáo viên và phụ huynh; huy động nguồn lực để xây dựng cơ sở vật chất phục vụ hoạt động GDHN, xây dựng tài liệu, tập huấn đội ngũ giáo viên mầm non, tuyên truyền nâng cao nhận thức của người dân, trong đó có các bậc cha mẹ trẻ,...

\section{Tài liệu tham khảo}

[1] The Government, Decision Approving the Project Career-oriented Education and Student Division Orientation in General Education Period 2018 -2025, 2018 (in Vietnamese).

[2] J. Curry, A. Milsom, Career Counseling in P-12 Schools, http://www.ebrary.com.ezproxy2.drake.b rockport.edu/, 2013 (accessed on: September $\left.12^{\text {th }}, 2020\right)$.

[3] S. D. Brown, R. W. Lent (eds.,), Career Development and Counseling: Putting Theory and Research to Work,

http://www.ebrary.com.ezproxy2.drake.brockport, edu/, 2012 (accessed on: September 12 ${ }^{\text {th }}, 2020$ ).

[4] F. Parsons, Choosing a Vocation, Boston, MA: Houghton Mifflin, 1909.

[5] A. F. Cabrera, S. M. L. Nasa, On the Path to College: Three Critical Tasks Facing America's Disadvantaged, Research in Higher Education, Vol. 42, 2001, pp. 119-150, https://doi.org/10.1023/A:1026520002362.

[6] Y. Nhi, Practical Experience for Preschool Children, http://baocamau.com.vn/giao-duc/trainghiem-thuc-te-cho-tre-mam-non-65738.html/, 2020 (accessed on: September 12 $2^{\text {th }}$ 2020) (in Vietnamese).

[7] P. Tuyet, Practical Experience for Preschool Children: Practical but must be Safe, https://congannghean.vn/van-hoa-giaoduc/201812/trai-nghiem-thuc-te-cho-tre-mamnon-thiet-thuc-nhung-phai-an-toan-828235/index. $\mathrm{htm} /, 2018$ (accessed on: September 12 $2^{\text {th }}, 2020$ ) (in Vietnamese).

[8] T. Xuan Kindergarten, Kindergarten Children with Career Experience Activities in Kizciti, https://edu.viettel.vn/hni-socsonmnthanhxuan/gioi-thieu/thong-tin-ba-congkhai/cac-be-truong-mam-non-thanh-xuan-voihoat-dong- h.html/, 2020 (accessed on: September $\left.12^{\text {th }}, 2020\right)$ (in Vietnamese).

[9] P. Gia, The First Career Play Zone Model in Vietnam - Kizciti,

https://khuvuichoihuongnghiep.com/mo-hinh-khuvui-choi-huong-nghiep-kizciti/, 2017 (accessed on: September 12 $\left.{ }^{\text {th }}, 2020\right)$ (in Vietnamese).

[10] Ministry of Education and Training, Education and Training Program: Experiential Activities, Experiential Activities, Career Guidance (Enclosed with Circular No. 32/2018/TT-BGDĐT Dated December 26, 2018), 2018a (in Vietnamese). 